\title{
Public Intervention in the Deployment of NGNs
}

\author{
José Luis Gómez-Barroso ${ }^{1}$ and Claudio Feijóo ${ }^{2}$ \\ ${ }^{1}$ UNED - Universidad Nacional de Educación a Distancia, Spain \\ ${ }^{2}$ Universidad Politécnica de Madrid, Spain \\ jlgomez@cee.uned.es, cfeijoo@cedint.upm.es
}

\begin{abstract}
The deployment of NGNs (Next Generation Networks) has led to a change for the public role in the telecommunications industry. Now the public support is seen as not only responsible for the regulatory framework where market forces thrive, but as the leading force behind infrastructure deployment and innovative boosting measures. This section reviews the ways in which involvement of public administrations in the deployment of NGNs is happening. Subsequently, it focuses on the analysis of the European case and particularly on the Guidelines for the application of State aid rules in relation to rapid deployment of broadband networks that the European Commission published on Sept. 2009.
\end{abstract}

Keywords: telecommunications, next generation networks, public intervention, infrastructure deployment, public funds, State aid, broadband.

\section{$1 \quad$ Introduction}

Public activity in the telecommunications sector in the $21^{\text {st }}$ century has experienced reorientations of certain importance, when compared with what was considered the norm at the end of the previous century. Aspirations for the benefits of an information society, evidence of different types of digital divides, and the need to move to a knowledge-based economy to maintain economic growth ${ }^{1}$ and quality of life all influence a renewed interest in public involvement in the domain.

Programs intended to facilitate the development of the information society have been used as an umbrella for most of these resuscitated initiatives. In all of these plans, access to advanced telecommunications networks is mainly left to market forces [1]. This is the case particularly for "traditional" broadband services. However, problems related to the deployment of next-generation access (NGA) networks are considered conceptually distinct. These are problems that many can be considered as insurmountable without public involvement, which puts stress on policy-makers.

\footnotetext{
${ }^{1}$ On the occasion of the presentation of the Connecting Europe Facility (see next footnote), Neelie Kroes, Vice-President of the European Commission responsible for the Digital Agenda, affirmed that "over just ten years, the right broadband development could give Europe over one trillion Euro in additional economic activity, and create millions of jobs. An increase in broadband penetration of 10 percentage points would increase Europe's annual GDP growth by between 0.9 and $1.5 \%$ ".
} 
As a consequence, there have been frequent allocations of public funds for the construction of infrastructure generally in places where it is believed that the market will not suffice, although similar projects can even be found in places where telecommunication operators maintain the availability of broadband connections under normal market conditions ${ }^{2}$.

One of the most significant characteristics of this public "comeback" in the deployment of telecommunication networks is the fact that the decisions are being made, in most cases, by public entities at a "lower" level than that of the central government: regional authorities and especially local or town councils, who feel closer to the immediate needs of citizens $[2,3]$. Indeed, many particular projects have been carried through autonomously without support from any national plans.

From a technological standpoint, the commercial maturity of some wireless standards, along with the resulting cost reductions, has actually multiplied the number of cases of broadband public networks using the radio spectrum [2, 3]. However, wireless technologies are not the only ones being used. There exist many examples of public administrations having driven forward or contributed to the deployment of cable or fiber [4]. Indeed, the scale is tilting towards wired technologies as NGA networks are introduced into the formula. Particularly illustrative to this respect are the Guidelines for the application of State aid rules in relation to the rapid deployment of broadband networks that the European Commission published on September 30, 2009, which will be analyzed in Section $3^{3}$.

In terms of practical matters, there are no common rules governing how to sponsor the construction of these networks or manage them once they are completed. The strategies being deployed are diverse and basically depend on the specific circumstances of each case [5]. Importantly, many of the current public interventions involve private initiatives, including public-private partnerships [6].

Besides direct intervention in the deployment of infrastructures, there is a whole array of other policy instruments that can support the development of NGA networks. Most of plans also include support for adoption strategies, where public

${ }^{2}$ At the time of editing this contribution, the European Commission itself announced the investment of $€ 9.2$ billion from 2014 to 2020 on pan-European projects "to give EU citizens and businesses access to high-speed broadband networks and the services that run on them" At least $€ 7$ billion would be available for investment in high-speed broadband infrastructure. The funding, part of the proposed Connecting Europe Facility, would take the form of both equity and debt instruments and grants, "complementing" private investment and public money at local, regional and national level and EU structural or cohesion funds.

3 Indeed, as stated in next section, a specific definition of the NGA is given in the Guidelines: they are cabled networks. However, in a Communication of 2006 ("Bridging the broadband gap") the European Commission itself had written: "The optimal mix of technologies depends on the characteristics of each particular location. The cost of technologies varies according to the number of potential users, the distance of the dwellings from the point of presence, and the presence of the backhaul. A scarcely-populated isolated area may be better off with a wireless solution and a small town with a wireline solution (...) No specific technology option will offer the best connectivity in all situations. The optimum is often achieved by a combination of technologies and solutions". 
administrations, in addition to taking on direct and arbitrator roles, use indirect intervention in the electronic communications market, encouraging demand and improving the conditions for the supply activity of private players. For instance, the role of local governments is manifold. The most well-known and analyzed among these "municipal interventions" is the deployment of municipal broadband networks [7, 8]. But they also can contribute to the collection of information to create a precise map of available infrastructures and the uptake of interested users. They can help aggregate local demand, and they know local topography and therefore may contribute to the determination of the optimal technology mix or may synchronize civic works. More, they can also develop local public services, take part in pilot projects or living labs to explore new technologies and new interests of users, or even support the rollout of next generation infrastructures.

In this regard, it is also worthwhile to remember that many digital policies (eInclusion, eHealth, eGovernment, eParticipation) share the same basic axiom of preventing exclusion, which was originally part of the universal service approach, although a more balanced view of access/supply and adoption/demand is now prevalent. Therefore, the relationship between public and private can (and should) be put in a wider, more social and citizen-centric context. Understanding these new relationships is key to the development of NGA because they are no longer isolated from issues of general socio-economic welfare: NGA infrastructures are not an end in themselves; they are usually deemed an intermediate step to increase and widen innovation, to create new opportunities for employment and, to contribute broadly to productivity, economic growth, social equity and sustainability.

\section{Promoting Investments in NGNs}

On September 30, 2009, the European Commission published Guidelines for the application of State aid rules in relation to the rapid deployment of broadband networks. These Guidelines are applicable to two markets that are connected, although different: "traditional" or "first generation" broadband networks (both terms are used in the Guidelines) and next-generation access (NGA) networks ${ }^{4}$. In the next sections, these Guidelines are analyzed in order to clarify the conditions required by the European Commission to accelerate the deployment of NGA networks ${ }^{5}$. Despite the fact that the title of these Guidelines specifically refers to "the application of the rules on State aids", the truth is that their content describes in detail different procedures for public funding, which are not exclusively limited to State aid in a strict sense.

\footnotetext{
${ }^{4}$ According to the Guidelines, NGA networks are "wired access networks which consist wholly or in part of optical elements and which are capable of delivering broadband access services with enhanced characteristics (such as higher throughput) as compared to those provided over existing copper networks".

${ }^{5}$ On April 2011, the Commission launched a public consultation on the revision of the Guidelines. The Guidelines foresee their revision by September 2012 "on the basis of important market, technological and regulatory developments".
} 


\subsection{Use of Public Funds That Do Not Constitute State Aid}

According to Article 107(1) of the Treaty on the functioning of the European Union, State aid is "any aid granted by a Member State or through State resources in any form whatsoever which distorts or threatens to distort competition by favoring certain undertakings or the production of certain goods shall, in so far as it affects trade between Member States, be incompatible with the internal market" (see $[9,10])$. It follows that in order for a measure to qualify as State aid, the following cumulative conditions have to be met: (a) the measure has to be granted out of State resources; (b) it has to confer an economic advantage to undertakings; (c) the advantage has to be selective and distort or threaten to distort competition; (d) the measure has to affect intra-Community trade.

Aid outside the scope of Article 107(1) (i.e. aid that does not have all four conditions) includes State support of the roll-out of broadband by way of an equity participation or capital injection into a company that is to carry out the project, the case where Member States consider that the provision of a broadband network should be regarded as a service of a general economic interest (SGEI), or general measures available to all economic undertakings in all parts of the Member State.

\subsubsection{Investment}

Following the principle of equal treatment (and according to the case-law of the Court of Justice of the European Communities), the Guidelines establish that capital placed by the State, directly or indirectly, at the disposal of an undertaking "in circumstances which correspond to normal market conditions" cannot be regarded as State aid [11].

The conformity of a public investment with the application of the "market economy investor principle" has to be demonstrated by the following means:

- The existence of a sound business plan showing an adequate return on investment.

- Significant participation of private investors who take part in the project and assume the commercial risk linked to the investment under the same terms and conditions as the public investor.

\subsubsection{Imposition of a Service of a General Economic Interest (SGEI) Mission}

The determination of the nature and scope of an SGEI mission falls within the competence and discretionary powers of Member States. However, such competence is "neither unlimited nor can it be exercised arbitrarily", which, in the case of broadband networks, means that "in areas where private investors have already invested in a broadband network infrastructure (or are in the process of expanding further their network infrastructure) and are already providing competitive broadband services with an adequate broadband coverage, setting up a parallel competitive and publiclyfunded broadband infrastructure should not be considered as an SGEI".

However, public service compensation may be granted to an undertaking entrusted with the operation of an SGEI on the condition that it can be demonstrated that private investors may not be in a position to provide adequate broadband coverage to all citizens or users in the "near future" (understood as referring to a period of 3 years). 
According to the case-law of the Court, State funding for the provision of an SGEI may not be regarded as State aid, provided that four conditions are met. Those conditions are commonly referred to as "the Altmark criteria" [12, 13]:

a) the beneficiary of a State funding mechanism for an SGEI must be formally entrusted with the provision and discharge of an SGEI, the obligations of which must be clearly defined;

b) the parameters for calculating the compensation must be established beforehand in an objective and transparent manner;

c) the compensation cannot exceed what is necessary to cover all or part of the costs incurred in the discharge of the SGEI, taking into account the relevant receipts and a reasonable profit; and

d) where the beneficiary is not chosen pursuant to a public procurement procedure, the level of compensation granted must be determined on the basis of an analysis of the costs that a typical "well-run" undertaking would have incurred.

The first of the criteria demands "clearly defined obligations". In the deployment of broadband networks, there are at least two obligations: to connect all citizens and businesses, and to make the network available for all interested operators, allowing effective competition at the retail level (the publicly funded network should be a passive, neutral and open-access infrastructure).

\subsubsection{Other Alternatives}

Member States may decide to adopt a set of measures to accelerate the NGA investment cycle and, thus, encourage investors to advance their investment plans. Specifically, this consists of carrying out civil works. Indeed, a large part of the cost of deploying telecommunication networks (particularly fiber networks) is incurred in digging, laying down cables or installing in-house wiring. In this respect, Member States may decide, for instance, to undertake some works such as digging of the public domain, or construction of ducts. For this practice to be admissible, such civil works should not be "industry or sector specific" but should be open to all potential users and not just electronic communications operators (e.g., electricity, gas or water utilities).

The Guidelines also mention options such as easing the acquisition process of rights of ways or demanding that network operators coordinate their civil works and/or share part of their infrastructure. Note, however, that these are regulatory measures that do not require any public funds to be paid out.

\subsection{State Aid}

A part of the State aids granted for the deployment of broadband networks could be considered to be included in the exception stated in item a) of article 107 , section 3 , of the Treaty on the functioning of the European Union ("aid to promote the economic development of areas where the standard of living is abnormally low or where there is serious underemployment"). However, it is item c) of this section that makes generally acceptable the aid granted by the States for these projects ("aid to facilitate 
the development of certain economic activities or of certain economic areas, where such aid does not adversely affect trading conditions to an extent contrary to the common interest").

In assessing whether any specific measure can be deemed compatible with the common market, the Guidelines for the broadband aids set out a background defined through a "colored area" analysis:

- "White" areas are those where broadband is currently not available and where there are no plans by private investors to roll out such an infrastructure in the near future.

The term "in the near future" should be understood as referring to a period of three years. In this regard, investment efforts planned by private investors should not guarantee that significant progress in terms of coverage will be made within the three-year period (with completion of the planned investment foreseen within a reasonable time frame thereafter).

In the Guidelines it is recognized that the Commission has taken an overwhelmingly favorable view towards State measures for broadband deployment for underserved, typically rural, areas.

- "Grey" areas are those where only one broadband network operator is present.

In these situations, State support for the deployment of broadband networks calls for "a more detailed analysis and careful compatibility assessment" (as monopoly provision "may affect the quality of service or the price at which services are offered to the citizens", but, on the other hand, subsidies for the construction of an alternative network can distort market dynamics).

If more than one network will be deployed in the "near future" (the coming three years), such an area should, in principle, be considered black (see below).

- "Black" areas are geographical zones where at least two broadband network providers are present and where broadband services are provided under competitive conditions 6 .

In black NGA areas, the wording is clear: "no need for State intervention".

It is important to underline that the case of white NGA areas were, at the moment where the Guidelines were published, the rule in the European Union. Note also that part of the areas that are grey and even black for the traditional broadband are white for the NGA networks, as there has been no deployment in these areas. For cases where there is a "change of color", the Guidelines establish "compatibility" rules:

- In traditional grey areas (but white NGA areas), the grant of aid for NGA networks is subject to the demonstration by the Member State concerned that "the planned NGA network is not or would not be sufficient to satisfy the needs of citizens and business users in the areas in question" (also taking into account a possible future upgrade).

\footnotetext{
${ }^{6}$ Therefore, facilities-based competition exists. There could also exist competition at the level of services in grey areas, should the single network be open to other operators.
} 
- In black (basic broadband) areas no further State intervention should in principle (same clarification again) be necessary, as "existing network operators should have the incentives to upgrade their current traditional broadband networks to very fast NGA networks to which they could migrate their existing customers".

Member States can rebut such an argument "by showing that existing basic broadband operators do not plan to invest in NGA networks in the coming three years by demonstrating for instance that the historical pattern of the investments made by the existing network investors over the last years in upgrading their broadband infrastructures to provide higher speeds in response to users' demands was not satisfactory".

It must be underlined that an additional qualification is made for projects to be authorized; they will be approved provided that there are no less distortive means (including ex ante regulation) to reach the stated goals.

If this requirement is met and a balancing test of the project concludes that the overall evaluation of it is positive, a number of fundamental conditions must be complied with to "minimize the State aid involved and the potential distortions of competition". These conditions are detailed mapping exercise and coverage analysis, open tender process, priority to the most economically advantageous offer, technological neutrality, re-use of existing infrastructure, mandated wholesale open access (for at least seven years) ${ }^{7}$, benchmarking exercises (with average published or regulated wholesale prices that prevail in other comparable areas of the country) and claw-back mechanisms (to ensure that the selected bidder is not overcompensated if the demand for broadband in the target area grows beyond anticipated levels).

\section{Summary and Conclusions}

The advent of the new socio-economic paradigm represented by the information society presents countries with risks and opportunities. The support for information technologies and service industries appears to be a sure path for future economic development. Indeed, this may be the only way for countries with narrow domestic markets or limited physical resources to prosperity. This general remark is particularly true in times of crisis, when countries are desperately searching for ways to return the economy to its growth path.

In this scenario, NGNs are regarded as a necessary tool for prosperity. This justifies a much more active intervention in the telecommunications industry's activity, and even allocating public funding for the deployment of networks [14]. Conceptually, this is nothing particularly new. Generalized access to telecommunication services has been, in general and regardless of the degree of success, an objective of every

\footnotetext{
${ }^{7}$ Whatever the type of the NGA network technical architecture, it should support effective and full unbundling and satisfy all different types of network access that operators may seek (including but not limited to access to ducts, fibre and the so-called "bitstream access"); in setting the conditions for wholesale network access, Member States should consult the relevant NRA.
} 
government during the last century [15]. This suggests that the advantages of a massive connection to telecommunication services have been understood regardless of the political option in power. What can indeed be considered a novelty as regards the general rule during the last decade, is the depth of the intervention. Following the complete liberalization of the markets it seemed to have been accepted that the activity of the private agents could only be complemented exceptionally to correct the "failures" of the offer in networks that were then almost universal [16]. Indeed, the contribution of public funds for the deployment of new networks did not seem foreseeable only a few years earlier, at least in developed countries.

However, the presently reinforced public intervention should not be done behind or regardless of the market. It is worthy of note that, in spite of the supply-side focus of many plans, uncertainties about the demand subsist, thus arguing for more integrated approaches and not just the simple deployment of NGNs. The, up to now, unremitting impact of the economic crisis in the capacity of expenditure of public administrations is leading also to look for the best conditions for the public investment.

Open Access. This article is distributed under the terms of the Creative Commons Attribution Noncommercial License which permits any noncommercial use, distribution, and reproduction in any medium, provided the original author(s) and source are credited.

\section{References}

1. Gómez-Barroso, J.L., Feijóo, C., Karnitis, E.: The European policy for the development of an information society: the right path? Journal of Common Market Studies 46(4), 787-825 (2008)

2. Strover, S., Mun, S.H.: Wireless broadband, communities, and the shape of things to come. Government Information Quarterly 23(3-4), 348-358 (2006)

3. Troulos, C., Maglaris, V.: Factors determining municipal broadband strategies across Europe. Telecommunications Policy 35(9-10), 842-856 (2011)

4. Ehrler, M., Ruhle, E.O., Brusic, I., Reichl, W.: Deployment of fibre optic networks within the framework of public-private partnerships projects. International Journal of Management and Network Economics 1(3), 308-326 (2009)

5. Ragoobar, T., Whalley, J., Harle, D.: Public and private intervention for next-generation access deployment: Possibilities for three European countries. Telecommunications Policy 35(9-10), 827-841 (2011)

6. Falch, M., Henten, A.: Public private partnerships as a tool for stimulating investments in broadband. Telecommunications Policy 34(9), 496-504 (2010)

7. Mandviwalla, M., Jain, A., Fesenmaier, J., Smith, J., Weinberg, P., Meyers, G.: Municipal broadband wireless network. Communications of the ACM 51(2), 72-80 (2008)

8. Goth, G.: Municipal wireless gets new emphasis - Rethinking the infrastructure cloud. IEEE Internet Computing 13(6), 6-8 (2009)

9. Friederiszick, H.W., Röller, L.H., Verouden, V.: European state aid control. An economic framework. In: Buccirossi, P. (ed.) Handbook of Antitrust Economics, pp. 625-669. MIT Press, Cambridge (2008)

10. Kurcz, B., Vallindas, D.: Can general measures be... selective? Some thoughts on the interpretation of a state aid definition. Common Market Law Review 45(1), 159-182 (2008) 
11. Parish, M.: On the private investor principle. European Law Review (1), 70-89 (2003)

12. Renzulli, A.: Services of general economic interest: The post-'Altmark scenario'. European Public Law 14(3), 399-432 (2008)

13. Klages, R., Alemanno, A., Falcone, N., Petit, N., Ballester, R.: Services économiques d'intérêt général (arrêt 'Altmark Trans GmbH'); Revue du Droit de l'Union Européenne, No. 2003-3, pp. 755-759 (2003)

14. Cave, M., Martin, I.: Motives and means for public investment in nationwide next generation networks. Telecommunications Policy 34(9), 505-512 (2010)

15. Gómez-Barroso, J.L., Feijóo, C.: A conceptual framework for public-private interplay in the telecommunications sector. Telecommunications Policy 34(9), 487-495 (2010)

16. Gómez-Barroso, J.L., Pérez-Martínez, J.: Public intervention in the access to advanced telecommunication services: assessing its theoretical economic basis. Government Information Quarterly 22(3), 489-504 (2005) 